\title{
Variant Selection of Reversed Austenite in Lath Martensite
}

\author{
Nobuo NAKADA, ${ }^{1)}$ Toshihiro TSUCHIYAMA, ${ }^{1)}$ Setsuo TAKAKI ${ }^{11}$ and Shuji HASHIZUME ${ }^{2 \prime}$ \\ 1) Department of Materials Science and Engineering, Kyushu University, 744 Motooka, Nishi-ku, Fukuoka $819-0395$ Japan. \\ 2) R \& D, Tenaris NKK Tubes, 1-10 Minamiwatarida-cho, Kawasaki, Kanagawa 210-0855 Japan.
}

(Received on July 9, 2007; accepted on August 16, 2007)

\begin{abstract}
The microstructure of partially reversed lath martensite in $13 \% \mathrm{Cr}-6 \% \mathrm{Ni}$ steel was examined by electron backscatter diffraction, and the crystallographic character of the reversed austenite is discussed in relation to the mechanism of 'austenite memory'. Most of the reversed austenite grains had the same orientation as the original austenite matrix before martensitic transformation. However, some austenite grains had a different orientation in a twin relationship to the other major austenite grains, although all the reversed austenite grains retained a Kurdjumov-Sachs relationship to the martensite matrix. On the basis of the crystallographic relationships among the habit plane, the close packed direction of austenite and the martensite lath boundary, we suggest that the austenite variants are theoretically limited to two kinds within one packet and five kinds within one original austenite grain. In addition, we found that internal stress introduced by martensitic transformation plays an important role in determining the austenite variant: internal stress operates so that reversed austenite selects the same variant as that present in the original austenite matrix before martensitic transformation. This phenomenon is understood as the austenite memory.
\end{abstract}

KEY WORDS: austenite memory; variant selection; martensite; reversion; Kurdjumov-Sachs relationship; internal stress.

\section{Introduction}

Reversion from martensite $\left(\alpha^{\prime}\right)$ to austenite $(\gamma)$ is often applied in steel production as one of the most effective methods for grain refinement. In martensitic and bainitic steels, however, austenite grains of a single type are usually formed with an identical crystallographic orientation in one prior austenite grain ${ }^{1-12)}$; these finally combine to form one coarse austenite grain that is similar in size to the original austenite grain. ${ }^{6,7)}$ This phenomenon is called 'austenite memory' ${ }^{7-9)}$ Such a behavior is not favorable in terms of grain refinement; hence, it is important to elucidate the reversion mechanism and identify the factors that control the austenite memory in martensitic and bainitic steels. In previous studies, three types of mechanism have been proposed for the austenite memory: (1) reversibility by nondiffusional shear reversion from martensite to austenite (the shear reversion mechanism $)^{10,11)}$; (2) variant restriction by crystallographic orientation relationship among constituent phases (the variant restriction mechanism) ${ }^{12)}$; and (3) growth of slightly retained original austenite (the retained austenite mechanism). ${ }^{7,9)}$ The shear reversion mechanism is based on the reversibility of crystallographic orientation in non-diffusional martensitic transformations, which results in the formation of austenite grains with the same orientation as the original austenite. The variant restriction mechanism has been proposed for steels containing cementite; diffusive austenite nucleation occurs with a special crystallographic orientation relationship among austenite, cementite and the matrix. This leads to a strict restriction on the variant selection of reversed austenite. The retained austenite mechanism has been proposed for the case of a martensitic steel containing carbon. Small amounts of austenite are retained even after martensitic or bainitic transformation, and these grow and reverse again to the original large austenite grain.

One of the reasons for this confusion of understanding is in the experimental procedure. Many researchers have built up their mechanisms on the basis of microstructural analysis within a small area by transmission electron microscopy (TEM). TEM is very useful for the analysis of the magnified microstructure, but is not suitable for the analysis of the large scale microstructure. To elucidate the austenite memory mechanism, crystallographic characteristics of reversed austenite have to be discussed in a wider area covering an entire prior austenite grain.

In this study, we prepared an ultralow carbon martensitic steel (Fe-13mass\%Cr-6mass\%Ni alloy) and studied the distribution of austenite grains in this alloy in partially reverted specimens by the electron backscatter diffraction (EBSD) method. From the EBSD results, we discuss the mechanism of austenite memory in connection with austenite variant restriction in the nucleation stage, and we examined the effect of internal residual stress on the nucleation behavior of reversed austenite.

\section{Experimental Procedure}

The $13 \mathrm{Cr}-6 \mathrm{Ni}$ steel prepared in this study $(\mathrm{Fe}-$ 13 mass $\% \mathrm{Cr}-6 \mathrm{mass} \% \mathrm{Ni}-0.012 \mathrm{mass} \% \mathrm{C}-0.012$ mass $\% \mathrm{~N}-$ 
2.1mass\%Mo alloy) is an ultralow carbon martensitic stainless steel similar to that used to in oil-well piping. To obtain a martensitic single structure, the material was waterquenched after a solution treatment at $1173 \mathrm{~K}$ for $1.8 \mathrm{ks}$ in the austenite single phase region, and then subjected to a partial reversion treatment at $913 \mathrm{~K}$ in the (ferrite + austenite) two-phase region. This material is appropriate for the investigation of the crystallographic analysis of reversed austenite for the following reasons.

(1) A fully lath martensitic single structure is easily obtained by water-quenching, because of the high hardenability of the material. The austenite to martensite transformation temperature $M_{\mathrm{s}}$ of this material is about $500 \mathrm{~K}$, and austenite is hardly retained after the water-quenching treatment (i.e., there is no possibility of the retained austenite mechanism). ${ }^{13)}$

(2) Because of the ultralow carbon content of the material, cementite is not formed during the reversion treatment. If cementite or the other kinds of carbide were formed, their volume fractions would be negligible (i.e., there is no possibility of the variant restriction mechanism as a result of the existence of cementite).

(3) Reversed austenite can be retained stably at ambient temperature because $\mathrm{Ni}$ condenses into the reversed austenite during the reversion treatment. ${ }^{14)}$ This result suggests that the reversed austenite is formed by a diffusional mechanism (i.e., there is no possibility of the shear reversion mechanism).

(4) The two-phase region (ferrite +austenite) is wider at lower temperatures as a result of the addition of nickel, so that only nucleated small austenite particles can be observed in specimens held at a low temperature of about $900 \mathrm{~K}$.

The microstructure of the samples was examined by optical microscopy, scanning electron microscopy (SEM) and TEM. Crystallographic characterization was also carried out by means of the EBSD method using a field-emission scanning electron microscope. The results obtained by EBSD method were analyzed by means of the Orientation Imaging Microscopy $\left(\mathrm{OIM}^{\mathrm{TM}}\right)$ system. The volume fraction of austenite phase was measured by thermodilatometry, Xray diffractometry with $\operatorname{CoK} \alpha$ radiation, and saturation magnetization measurements. ${ }^{15)}$ To determine the effect of stress on the reversion behavior, attempts were made to investigate stress loading during partial reversion treatment with a Lever-type creep-testing machine for test pieces with a gauge section of $\phi 3 \mathrm{~mm} \times 10 \mathrm{~mm}$.

\section{Results}

\subsection{Martensitic Structure after Solution Treatment}

Figure 1 shows an optical (a) and a TEM micrograph (b) of a specimen subjected to water quenching after the solution treatment. The specimen has a typical lath martensitic structure with the prior austenite grain size of approximately $30 \mu \mathrm{m}$. The morphology of martensite packets and blocks agree with the characteristic of ultralow carbon martensitic steels, as classified by Maki et al. ${ }^{13)}$ No retained austenite was observed in the TEM image or the electron diffraction pattern. In addition, the saturated magnetization was unchanged, even after cold rolling of $50 \%$. This indi-

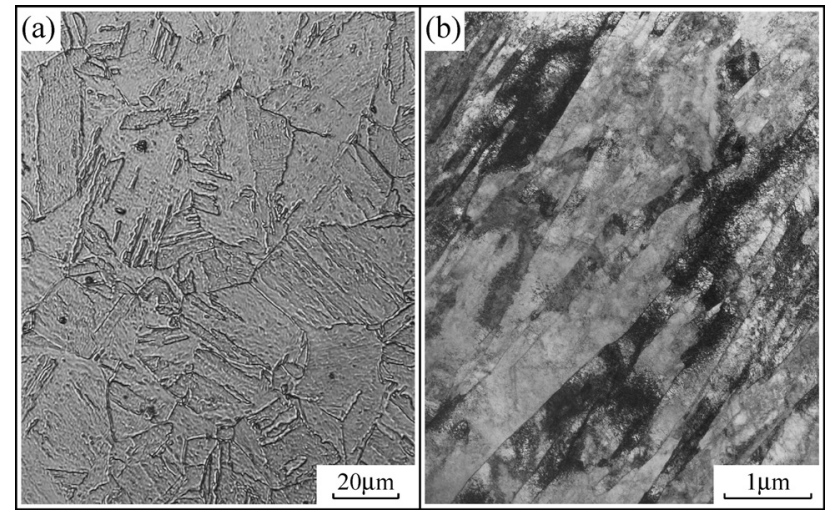

Fig. 1. Optical micrograph (a) and TEM image (b) of $13 \mathrm{Cr}-6 \mathrm{Ni}$ steel water-quenched after solution treatment at $1173 \mathrm{~K}$ for $1.8 \mathrm{ks}$

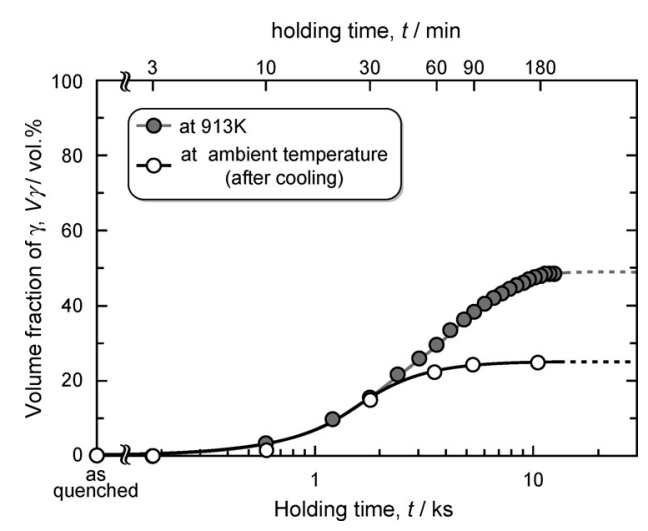

Fig. 2. Change in volume fraction of reversed austenite in $13 \mathrm{Cr}-6 \mathrm{Ni}$ steel during partial reversion treatment and after cooling.

cates that retained austenite did not exist after quenching of the steel to ambient temperature.

\subsection{Formation of Reversed Austenite in Lath Marten- sitic Structure}

Figure 2 shows changes in the volume fraction of austenite during holding at $913 \mathrm{~K}$ in the (ferrite + austenite) two-phase region $(\mathbf{O})$ and after air-cooling from $913 \mathrm{~K}(\mathrm{O})$, as a function of the holding time. The volume fraction of reversed austenite gradually increased with increasing holding time, and then finally leveled off at around $50 \mathrm{vol} \%$. Such a gradual reversion behavior is characteristic of a diffusional process. Martensitic shear reversion is characterized by a rapid change that does not depend on time, but depends only on the temperature change. ${ }^{16)}$ In addition, thermodynamic calculation with Thermo-calc revealed that the holding temperature of $913 \mathrm{~K}$ is slightly lower than the $T_{0}$ temperature. Therefore, there is no possibility of martensitic shear reversion. When the volume fraction of reversed austenite exceeds $20 \mathrm{vol} \%$ (holding time $>2.4 \mathrm{ks}$ ), partial retransformation to martensite occurs on cooling to ambient temperature (formation of fresh martensite). This is due to a lowering of the stability of reversed austenite as a result of dilution of $\mathrm{Ni}$ with an increase of austenite volume fraction. ${ }^{17)}$ Because the formation of fresh martensite confuses the crystallographic analysis, a reversion time $1.8 \mathrm{ks}$, giving $15 \mathrm{vol} \%$ of reversed austenite, was adopted for our subse- 


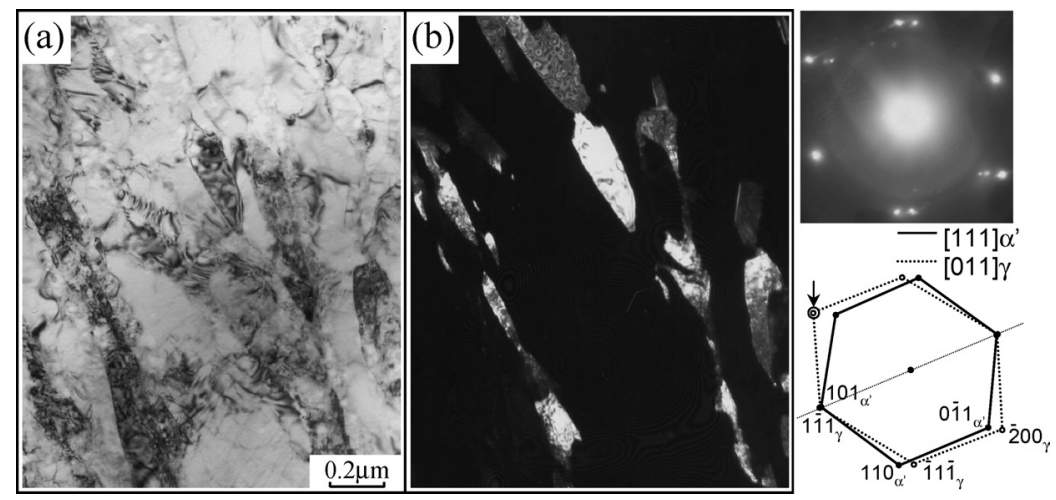

Fig. 3. Bright field (a) and dark field TEM image (b) of $13 \mathrm{Cr}-6 \mathrm{Ni}$ steel partially reversion treated at $913 \mathrm{~K}$ for $1.8 \mathrm{ks}$. The direction of the incident beam is roughly $\langle 111\rangle \alpha^{\prime}$ and $\langle 110\rangle \gamma$.

quent experiments.

Figure 3 represents the TEM bright field (a) and darkfield image (b) and the selected-area electron diffraction pattern and its key diagram. Acicular austenite grains were formed along martensite lath boundaries. The observed area just corresponds to the lath structure within one martensite block. The electron diffraction pattern indicated that reversed austenite grains had an identical orientation relationship with the martensite matrix, namely the Kurdjumov-Sachs (K-S) relationship $\left\{(111) \gamma / /(011) \alpha^{\prime}\right.$, $\left.[\overline{1} 10] \gamma / /[\overline{1} \overline{1} 1] \alpha^{\prime}\right\}$. Furthermore, X-ray energy dispersive spectroscopy (XEDS) showed the existence of Ni enrichment (by about 9.2 mass\%) in the reversed austenite (Fig. 4). The $M_{\mathrm{s}}$ of the reversed austenite was evaluated at $430 \mathrm{~K}$ from its chemical composition by means of Leslie's equation $^{18)}$ : this means that the reversed austenite is substantially unstable, but fairly stabilized owing to the spatial restriction effect. ${ }^{19,20)}$

\subsection{Variant Distribution of Reversed Austenite in the Martensite Matrix}

Figure 5 shows crystal orientation imaging maps of the partially reversed specimen. The dispersions of reversed austenite are shown in maps 5(b) and 5(d). The magnified images 5(c) and 5(d) correspond to the square area $\mathrm{A}$ in maps 5(a) and 5(b), respectively. In these maps, solid lines and broken lines follow prior austenite grain boundaries and packet boundaries, respectively. These maps reveal that reversed austenite grains are uniformly formed within a prior austenite grain, not only on lath boundaries, but also on packet boundaries and block boundaries. Note that most of the reversed austenite grains have a common crystallographic orientation within one prior austenite grain, as shown by the green color in map 5(b) (Variant $1 ; \mathrm{V}_{1}$ ). These austenite grains should grow with retention of their crystallographic orientation and finally coalesce with each other to form a large austenite grain of the same size as the original austenite grain - the so-called austenite memory. However, it is interesting that a small proportion of austenite grains have different orientations, as shown by the pink color in map 5(d) (Variant 2; $\mathrm{V}_{2}$ ).

Figure 6 represents (001) pole figures that explain the crystallographic character of the reversed $\mathrm{V}_{1}$ austenite. The open dots $(O)$ in pole Fig. 6(a) correspond to $\{001\} \gamma$ planes of $\mathrm{V}_{1}$ austenite, and the solid dots $(\mathbf{O}, 1-24)$ show

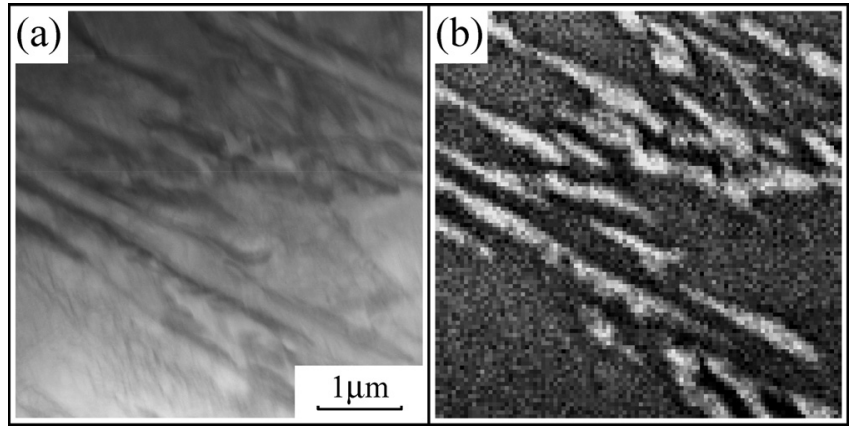

Fig. 4. Bright field image by STEM (a) and elemental mapping image (b) showing the enrichment by $\mathrm{Ni}$ of reversed austenite in $13 \mathrm{Cr}-6 \mathrm{Ni}$ steel partially reversion treated at $913 \mathrm{~K}$ for $1.8 \mathrm{ks}$.

the 24 possible $\{001\} \alpha^{\prime}$ planes of the body-centered cubic (bcc) phase that are in a $\mathrm{K}-\mathrm{S}$ relationship with the $\mathrm{V}_{1}$ austenite. $^{21)}$ On the other hand, pole Fig. 6(b) shows the $\{001\} \alpha^{\prime}$ planes of three blocks within one prior austenite grain, $M a, M b$, and $M c$, respectively, as marked in Fig. 5(a). A comparison of Figs. 6(a) and 6(b) indicates that the $\{001\} \alpha^{\prime}$ planes of $M a, M b$ and $M c$ almost correspond with solid dots 3, 2 and 21, respectively. This means that $\mathrm{V}_{1}$ austenite has a $\mathrm{K}-\mathrm{S}$ relationship with any block of $M a, M b$ and $M c$. As a result of similar analyses for many other blocks within one prior austenite grain, we confirmed that $\mathrm{V}_{1}$ austenite has an identifiable $\mathrm{K}-\mathrm{S}$ relationship to all the martensite blocks in a small misorientation range of less than $5^{\circ}$. This result suggests that the reversed $V_{1}$ austenite has the same orientation as the original austenite grain before martensitic transformation.

Meanwhile, Fig. 7 represents the result of an orientation analysis for the reversed $\mathrm{V}_{2}$ austenite. The orientations of $\mathrm{V}_{1}$ austenite, $\mathrm{V}_{2}$ austenite and the martensite block surrounding these austenites [Md in Fig. 5(c)] are shown in the pole figure. (111) $\mathrm{V}_{2}$ is almost parallel with $(111) \mathrm{V}_{1}$ and $(011) M d$, and (110) $\mathrm{V}_{2}$ is almost parallel with $(0 \overline{1} 1) \mathrm{V}_{1}$ and (111)Md. This result indicates that $\mathrm{V}_{2}$ austenite also has a $\mathrm{K}-\mathrm{S}$ relationship with the tempered martensite matrix as well as with $\mathrm{V}_{1}$ austenite, where the habit plane and the close packed direction correspond to $(011) \alpha^{\prime}$ and [1 $\left.1 \overline{1} 1\right] \alpha^{\prime}$, respectively. In this case, a twin relationship holds between $\mathrm{V}_{1}$ austenite and $\mathrm{V}_{2}$ austenite on the habit plane of the martensite matrix $\left[(111) \gamma / /(011) \alpha^{\prime}\right]$. 


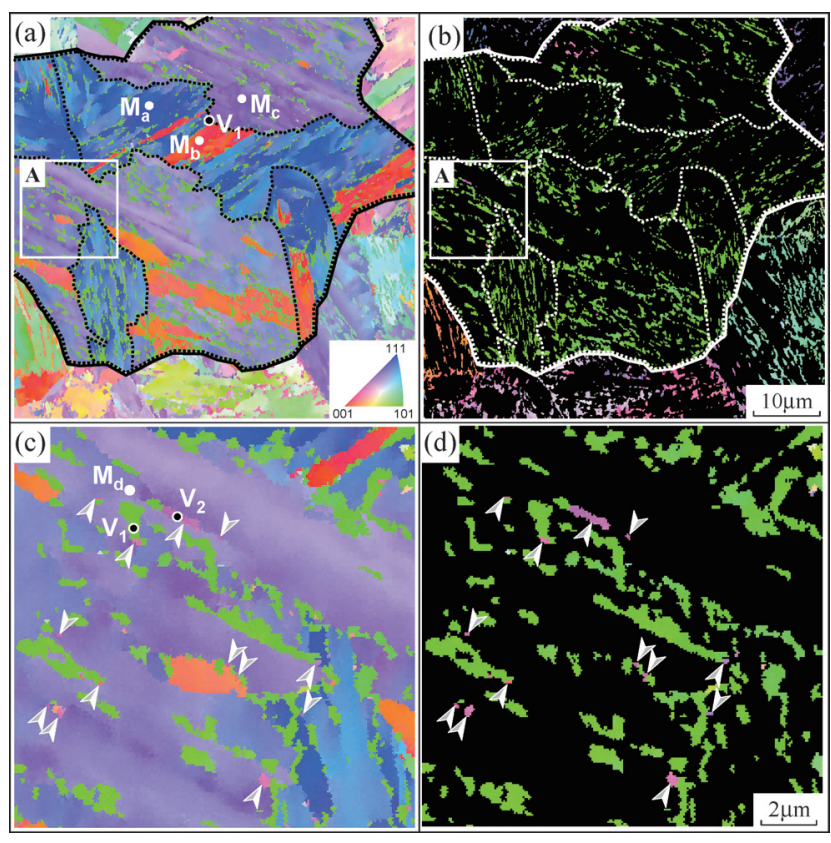

Fig. 5. Crystallographic orientation maps of $13 \mathrm{Cr}-6 \mathrm{Ni}$ steel partially reversion treated at $913 \mathrm{~K}$ for $1.8 \mathrm{ks}$. Maps (c) and (d) are the magnified versions of (a) and (b), respectively. Maps (a) and (c) show the martensite matrix and reversed austenite, whereas (b) and (d) show the reversed austenite only.
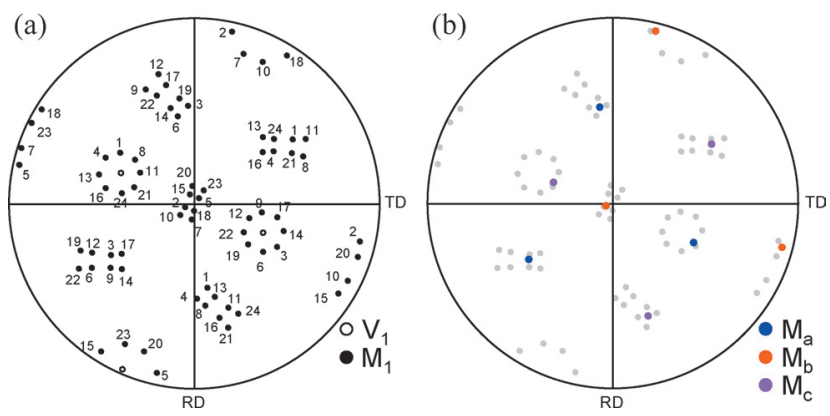

Fig. 6. (001) Pole figures for Variant 1 austenite $\left(\mathrm{V}_{1}, \mathrm{O}\right)$, possible variants of martensite under the $\mathrm{K}-\mathrm{S}$ relationship $\left(\mathrm{M}_{1}, \mathrm{O}\right)$ (a) and martensite blocks of $M a, M b$, and $M c$ shown in Fig. 5(a).

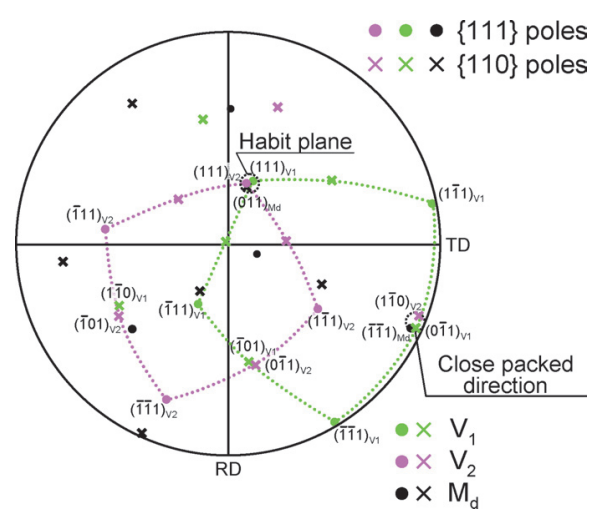

Fig. 7. Pole figure for Variant 1 austenite $\left(V_{1}\right)$, variant 2 austenite $\left(V_{2}\right)$ and the martensite block $(M d)$ surrounding these austenite grains shown in Fig. 5(c).

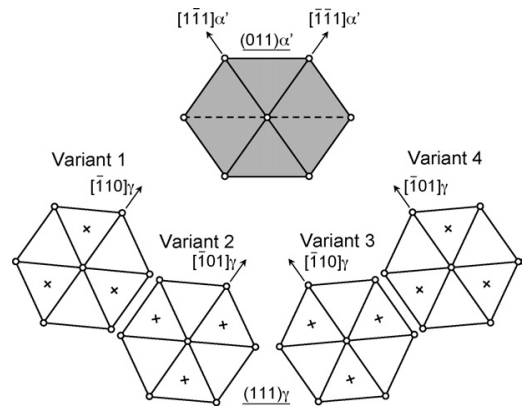

Fig. 8. Schematic showing austenite variants possible on a (110) $\alpha^{\prime}$ habit plane under the $\mathrm{K}-\mathrm{S}$ relationship.

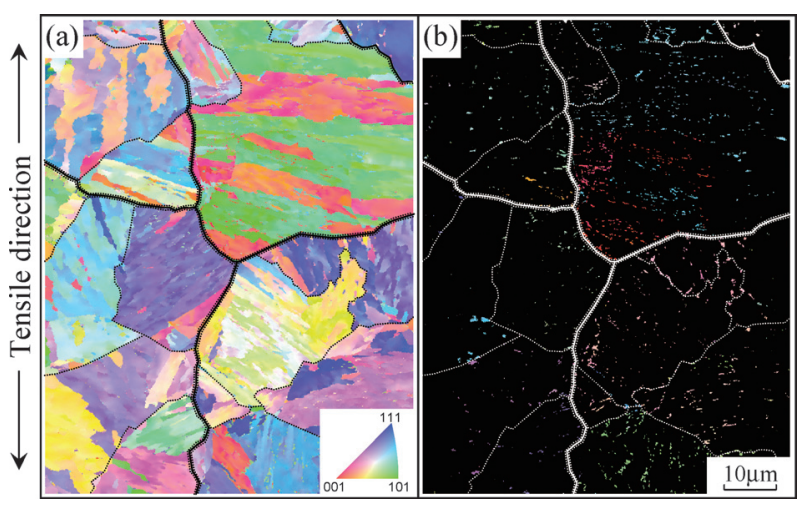

Fig. 11. Crystallographic orientation maps of $13 \mathrm{Cr}-6 \mathrm{Ni}$ steel subjected to partial reversion treatment at $913 \mathrm{~K}$ for $0.9 \mathrm{ks}$ under a uniaxial tensile stress of $100 \mathrm{MPa}$. (a) Martensite matrix and reversed austenite. (b) Reversed austenite shown only.

\section{Discussions}

\subsection{Variant Selection of Reversed Austenite in Terms of Crystallographic Orientation Relationship}

On the nucleation of austenite under the K-S relationship, four kinds of variant with different direction relationships are possible when the habit plane is fixed as (011) $\alpha^{\prime}$, as schematically illustrated in Fig. 8. $\left.{ }^{22}\right)$ Because the bcc structure has six crystallographically different $\{011\} \alpha^{\prime}$ planes, 24 variants of austenite could be formed on reversion from bcc to face-centered cubic. In the case of grain boundary precipitation, however, the variant of austenite is determined by the grain boundary plane: to reduce the activation energy for nucleation, one of the close packed planes that is nearly parallel to the grain boundary plane is selected as the habit plane. ${ }^{23,24)}$ The lath boundary plane (the wide plane of martensite lath) is close to the $\{011\} \alpha^{\prime}$ plane $^{25-28)}$ and acts as the habit plane for the nucleation of austenite. This means that one of $\{111\} \gamma$ planes should be parallel to this lath boundary plane. As a result of this strong habit plane restriction, the austenite variants within one martensite block are limited to four (Variants 1-4 in Fig. 8).

To explain austenite memory, other restriction rules must be added. On growth of austenite on the lath boundary plane, the $\alpha^{\prime} / \gamma$ interfacial energy can be minimized when austenite grown in one of the close packed directions $(\langle 011\rangle \gamma)$ becomes parallel to one of $\langle 111\rangle \alpha^{\prime}$; longitudinal direction of the martensite lath. ${ }^{27,28)}$ By adding this growth restriction to the habit plane restriction, the possibility of 


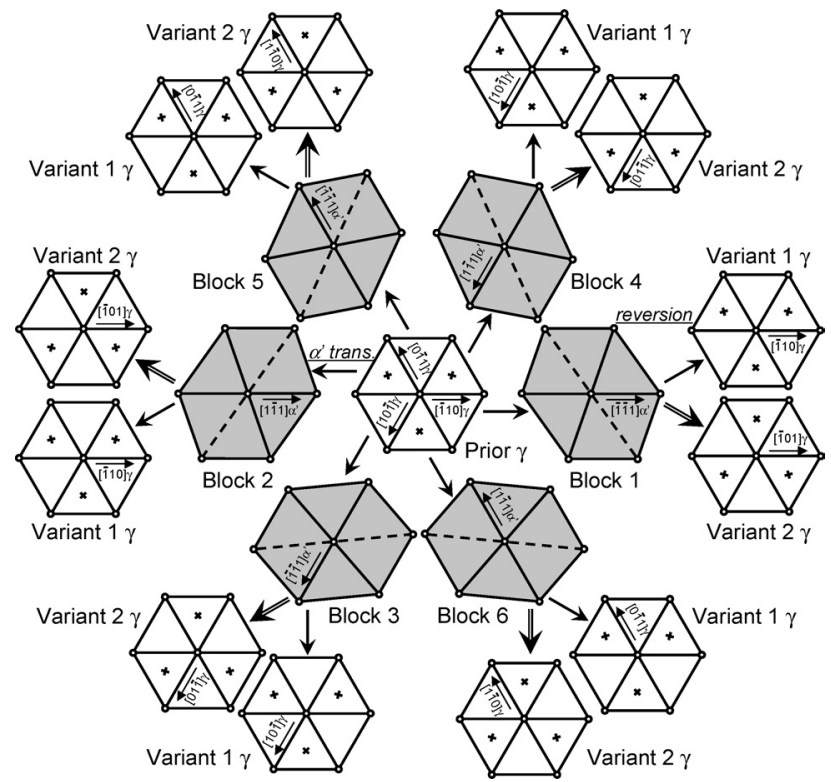

Fig. 9. Schematic showing the crystallographic relationship between a habit plane of prior austenite and the 12 variants of reversed austenite that are possible within one martensite packet containing blocks $1-6$.

austenite variants is limited to Variants 1 and 2 within one martensite block (Fig. 8). These two variants are in a twin relationship on the habit plane $\left[(111) \gamma / /(011) \alpha^{\prime}\right]$. Our experimental results agree well with this relationship.

Although the austenite variants are limited to two kinds within a martensite block, 24 kinds of blocks with different crystallographic orientation are theoretically possible within a prior austenite grain. ${ }^{29,30)}$ If each block has a completely different crystallographic plane and longitudinal direction, the total number of austenite variants should be 48 , and thus the occurrence of austenite memory would appear to be unlikely. However, these 48 kinds of austenite include some crystallographically equivalent variants. Figure 9 displays schematically the crystallographic relationship between a habit plane of prior austenite and those of the 12 austenite variants that are possible within one packet. Under the $\mathrm{K}-\mathrm{S}$ relationship, there are six blocks (Blocks 1 to 6) with different direction relationships parallel to the conjugate close packed planes, and each block has two types of reversed austenite selected by the variant restriction mechanism discussed above. This figure demonstrates that these 12 austenite variants in the packet can be classified into only $\mathrm{V}_{1}$ (same orientation as prior austenite) and $\mathrm{V}_{2}$ (twin relation to $\mathrm{V}_{1}$ ), owing to the threefold symmetry of austenite on the $\{111\} \gamma$ plane. By taking the other habit planes into account, the possible variants in one prior austenite grain are reduced to Variant 1 and four kinds of Variant 2 (i, ii, iii and iv), as shown three-dimensionally in Fig. 10 by means of Thompson's tetrahedron. The hatched planes correspond to the $\{111\} \gamma$ habit planes of four kinds of Variant 2 austenite (i to iv).

To summarize, the austenite variants should be theoretically limited to two kinds in a packet and five kinds in a prior austenite grain in terms of the crystallographic orientation relationship. Such a tendency has been certainly confirmed in our experimental result (Fig. 5), although it is difficult to observe Variant 2 (i to iv) because of its very low

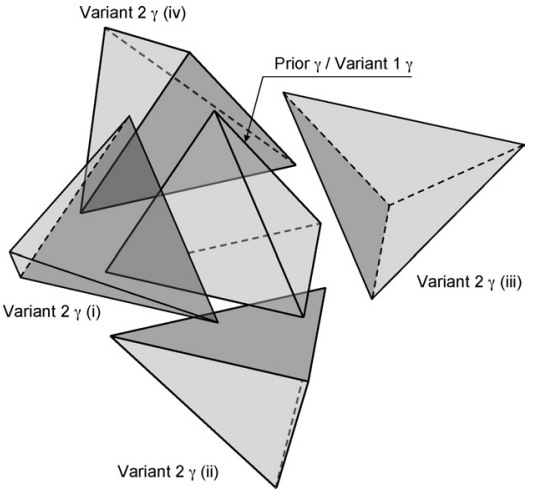

Fig. 10. Schematic showing the crystallographic relationship between a habit plane of prior austenite (Thompson's tetrahedron) and possible reversed austenite variants to the prior austenite.

frequency of appearance.

\subsection{The Effect of Internal Stress within Lath Marten- site on Variant Selection of Reversed Austenite}

The variant restriction mechanism mentioned above predicts the possibility of five kinds of variant for reversion in a prior austenite grain. However, most reversed austenite grains had the same orientation as that of the original austenite $\left(\mathrm{V}_{1}\right)$. This indicates that some factor promotes the formation of $\mathrm{V}_{1}$ austenite, and this cannot be explained in terms of the crystallographic orientation relationship alone. In the martensitic transformation, martensite blocks and packets with different crystallographic orientation are introduced to minimize the transformation strain, and this process results in the formation of a stratified martensitic structure comprising a prior austenite grain, packet, block, and lath. However, it is probable that some local residual stress remains within the martensite matrix. In terms of stress relief, reversion of martensite to original austenite should be most favorable.

To demonstrate the validity of this idea, stress-loading reversion was attempted as follows. Figure 11 represents the crystal orientation imaging maps of a specimen subjected to a partial reversion at $913 \mathrm{~K}$ for $0.9 \mathrm{ks}$ under a tensile stress of $100 \mathrm{MPa}$. Because the yield strength of this steel is approximately $240 \mathrm{MPa}$ at $913 \mathrm{~K}$, the applied stress is less than a half the yield stress. Prior austenite grain boundaries and packet boundaries are drawn in Fig. 11 by solid lines and broken lines, respectively. Unlike the result of Fig. 5, not only $V_{1}$ austenite, but also the other four variants of reversed austenite appear within each prior austenite grain. This means that the austenite memory is perturbed by external stress loading. Careful observation indicates that the variants of reversed austenite are limited to a maximum of two kinds within a packet. The effects of stress loading on the area fraction of $\mathrm{V}_{1}$ and $\mathrm{V}_{2}$ austenite are shown in Table 1. The area fraction of $V_{2}$ austenite is markedly increased by applying an external stress. This result indirectly demonstrates that the internal local residual stress promotes the formation of $\mathrm{V}_{1}$ austenite during reversion.

From these results, we conclude that the variant restriction mechanism for the austenite memory is reasonable in ultralow carbon martensite as well as in a steel containing 
Table 1. Effect of loading stress on variant selection in the reversion from martensite to austenite.

\begin{tabular}{|c|c||c|c|}
\hline \multicolumn{2}{|c||}{} & \multicolumn{2}{c|}{ Area fraction (\%) } \\
\cline { 2 - 4 } \multicolumn{2}{|c|}{} & $\begin{array}{c}\text { Variant1 } \\
(\text { prior } \gamma)\end{array}$ & $\begin{array}{c}\text { Variant2 } \\
\text { (twin relation) }\end{array}$ \\
\hline \multirow{2}{*}{$\begin{array}{c}\text { Without } \\
\text { loading }\end{array}$} & Grain1 & 99 & 1 \\
\cline { 2 - 4 } & Grain2 & 96 & 4 \\
\hline \multirow{3}{*}{$\begin{array}{l}100 \mathrm{MPa} \\
\text { stress loading }\end{array}$} & Grain1 & 50 & 50 \\
\cline { 2 - 4 } & Grain2 & 65 & 35 \\
\cline { 2 - 4 } & Grain3 & 62 & 38 \\
\hline
\end{tabular}

cementite. The existence of cementite provides a secondary regulation on diffusional phase transformation, and thus the austenite memory should appear more readily in steels containing cementite than in ultralow carbon martensite. However, note that internal residual stress plays an important role on the appearance of austenite memory in the case of martensitic steels.

\section{Conclusions}

The crystallographic characteristics of reversed austenite grains were investigated in ultralow carbon $13 \% \mathrm{Cr}-6 \% \mathrm{Ni}$ martensitic steel. The results obtained are summarized as follows.

(1) Reversed austenite grains are formed along lath boundaries as well as block boundaries and packet boundaries. Most of the reversed austenite grains within a prior austenite grain have a common crystallographic orientation. However, some austenite grains have a different orientation in a twin relationship to the major reversed austenite grains.

(2) All the reversed austenite grains show a Kurdjumov-Sachs relationship to the martensite matrix: by taking into consideration the crystallographic relations among the habit plane and the close packed direction of austenite and the martensite lath boundary, the kinds of austenite variant are theoretically predicted to be two kinds of variant in twin relation within a packet, and five kinds of variant within a prior austenite grain.

(3) We suggest that internal local residual stress plays an important role in the appearance of austenite memory, that is, the reversion of martensite to austenite with the same crystallographic orientation as that of the original austenite. We also confirmed that under an external stress loading, the austenite memory is confused and the other four variants of austenite appear more frequently.

\section{Acknowledgment}

This study was supported by the Research Promotion Grant of the Iron and Steel Institute of Japan.

\section{REFERENCES}

1) M. Baeyertz: Trans. ASM, 30 (1942), 458

2) A. E. Nehrenberg: Trans. AIME, 188 (1950), 162.

3) E. Kula and M. Cohen: Trans. ASM, 46 (1954), 727.

4) D. Webster and G. B. Allen: J. Iron Steel Inst., 200 (1962), 520.

5) R. Honma: Tetsu-to-Hagané, 58 (1972), 119.

6) V. D. Sadovskii: Problems of Physical Metallurgy and Heat Treatment, Mashgiz, Moscow, (1956), 31.

7) G. Shigesato, M. Sugiyama, T. Hara and H. Asahi: CAMP-ISIJ, 17 (2004), 1269.

8) V. D. Sadovskii and B. K. Sokolov: Problems of Physical Metallurgy and Heat Treatment, Mashgiz, Moscow, (1960), 5.

9) S. T. Kimmins and D. J. Gooch: Met. Sci., 17 (1983), 519.

10) S. S. D'Yachenko and G. V. Fedorov: Fiz. Met. Metalloved., 18 (1964), 73

11) S. Matsuda and Y. Okamura: Tetsu-to-Hagané, 60 (1974), 226.

12) S. Watanabe and T. Kunitake: Tetsu-to-Hagané, 61 (1975), 96.

13) T. Maki and I. Tamura: Tetsu-to-Hagané, 67 (1981), 852.

14) N. Nakada, J. Syarif, T. Tsuchiyama and S. Takaki: Mater. Sci. Eng. A, A374 (2004), 137.

15) S. Takaki, Y. Tokunaga and K. Tomimura: Tetsu-to-Hagané, 73 (1987), S539.

16) Z. Nishiyama: Martensitic Transformation, Marzen, Tokyo, (1971).

17) T. Ooka and K. Sugino: J. Jpn. Inst. Met., 30 (1966), 435.

18) W. C. Leslie: The Physical Metallurgy of Steels, McGraw-Hill, (1981).

19) S. Takaki, K. Fukunaga, J. Syarif and T. Tsuchiyama: Mater. Trans., 45 (2004), 2245.

20) N. Nakada, T. Yamashita, J. Syarif, T. Tsuchiyama and S. Takaki: Tetsu-to-Hagané, 89 (2003), 1050.

21) S. Morito, H. Tanaka, R. Konishi, T. Furuhara and T. Maki: Acta Mater, 51 (2003), 1789.

22) K. Ameyama, T. Maki and I. Tamura: J. Jpn. Inst. Met., 50 (1986), 10 .

23) P. R. Howell and R. W. K. Honeycombe: Proc. of an Int. Conf. on Solid-Solid Phase Transformation, TMS-AIME, Warrendale, PA, (1981), 399.

24) J. K. Lee and H. I. Aaronson: Acta Metall., 23 (1975), 809.

25) S. Takeuchi, T. Honma and S. Suzuki: J. Jpn. Inst. Met., 21 (1957), 51 .

26) A. H. Greninger and A. R. Troiano: Trans. AIME, 140 (1940), 307.

27) V. I. Izotov: Phys. Met. Metallogr. (USSR), 34 (1972), 112.

28) K. Wakasa and C. M. Wayman: Acta Metall., 29 (1981), 973.

29) J. M. Marder and A. R. Marder: Trans. ASM, 62 (1969), 1

30) S. Matsuda, T. Inoue, H. Mimura and Y. Okamura: Proc. of Int. Symp. toward Improved Ductility and Toughness, Kyoto, Japan, (1971), 47. 